\title{
Neologistic Jargon Sparing Numbers: A Category-specific Phonological Impairment
}

\author{
Laurent Cohen \\ Hôpital de la Salpêtrière, Paris, France \\ Patrick Verstichel \\ Hôpital Beaujon, Clichy, France \\ Stanislas Dehaene \\ INSERM Unité 334, Orsay, France
}

\begin{abstract}
We report the case of a patient suffering from a severe neologistic jargon sparing number words. Neologisms resulted from pervasive phoneme substitutions with frequent preservation of the overall syllabic structure (e.g. / revolver/ $\rightarrow$ /reveltil/). Word and nonword reading, as well as picture naming, were equally affected. No significant influence of frequency, imageability, and grammatical class was found. In striking contrast with this severe speech impairment, the patient made virtually no phonological errors when reading aloud arabic or spelled-out numerals, but made frequent word selection errors (e.g. $250 \rightarrow$ "four hundred and sixty"). This observation indicates that during speech planning, different categories of words are processed by separable brain systems down to the level of phoneme selection, a more peripheral level than was previously assumed. Number words may be singled out during phonological processing either because they constitute a particular semantic category, or because they benefit from special brain mechanisms devoted to the production of "automatic speech", or because they are the elementary building blocks of speech during the production of complex numerals.
\end{abstract}

\section{INTRODUCTION}

Recent research with brain-damaged patients, as well as functional brain imaging in normal subjects, has brought increasing support to the idea that

Requests for reprints should be addressed to Dr Laurent Cohen, Service de Neurologie 1, Pavillon Paul Castaigne, Hôpital de la Salpêtrière, 57 Bd de l'Hôpital, 75651 Paris CEDEX 13, France (Tel: + 33 (1) 421618 49/+33 (1) 421618 02; Fax: +33 (1) 442452 47; E-mail: laurent.cohen@psl.ap-hop-paris.fr). 
knowledge relative to different categories of words rests in separable brain regions (H. Damasio, Grabowski, Tranel, Hichwa, \& Damasio, 1996; Dehaene, 1995). As yet, such categorical organisation has been shown to prevail at two broad levels of representation. First, at the semantic level, fragments of knowledge that build up the meaning of words are stored in distinct cortical locations for different word categories. For instance, naming animals differing by subtle shape features strongly activates the early visual cortex, whereas naming familiar tools or generating action words activates areas related to movement planning or movement perception (Martin, Haxby, Lalonde, Wiggs, \& Ungerleider, 1995; Martin, Wiggs, Ungerleider, \& Haxby, 1996). Second, the anatomical layout of the connections that bind semantic knowledge on the one hand, and word forms on the other hand, also obeys a systematic categorical organisation. Thus, at least in the case of nouns, the word forms and the corresponding concepts activate one another through convergent two-way projections to the left inferotemporal region. This temporal convergence zone can be subdivided anatomically according to conceptual domains, such as familiar people, tools, etc, explaining why brain lesions can yield category-specific word finding or word comprehension difficulties (Caramazza, 1996; H. Damasio et al., 1996; Verstichel, Cohen, \& Crochet, 1996).

We report the case of a patient with severe neologistic jargon resulting from numerous phoneme substitutions occurring during the planning of verbal output. The impairment thus affected a relatively late stage of speech production, which might be expected to be common to all types of words. However, the production of number words was almost entirely free of phonological errors, but displayed word selection errors of a quite different type. We will argue that such a category-specific sparing suggests that the cerebral lexicon has a categorical organisation down to the phonological level.

Following presentation of clinical data, we will try to characterise the origin of phonological errors through a detailed analysis of the jargon. We will then turn to the patient's performance in number processing tasks. Finally, we will discuss the bearings that such a pattern may have on models of normal speech production, and particularly on the categorical organisation of phonological planning.

\section{CASE REPORT}

\section{Medical History}

The patient was a 76-year-old, right-handed, retired college teacher. He was admitted to hospital because his speech had suddenly turned into an incomprehensible jargon. Furthermore, he seemed not to hear what was told to him. A mild right brachio-facial motor deficit was noted, which receded within a day. Initial CT scan revealed the sequelae of an old, overlooked, right-hemispheric 
temporo-frontal infarct. A second CT scan performed 1 week later showed an additional recent infarct affecting the posterior part of the left superior and middle temporal gyri (Fig. 1).

\section{Language Assessment}

\section{General Description}

The patient's spontaneous speech had normal fluency, prosody, and articulation. Many words contained one or several phonological transformations. For instance, when attempting to say "quelques années" (a few years), he produced / te/ instead of /ane/. Other neologisms were impossible to relate conclusively to any specific word (e.g. j`/emitrem / de dire quelque chose" [I /emitrem / to say something]). Finally, there were some syntax errors, as well as rare word substitutions that could not be accounted for by phonemic errors. Additionally, the patient suffered from a major auditory deficit that included perception of speech as well as nonlinguistic sounds. He complained that he could hear but not understand what was told to him. Actually, he behaved almost as if he were deaf: he often did not orient to sudden noises, nor react to the call of his name.

The patient was given a French version of the Boston Diagnostic Aphasia Examination (Table 1). Due to the auditory deficit, all subtests of repetition and auditory comprehension were performed at floor level. The jargon affected identically all subtests requiring an oral response. The relatively high scores in word reading, semantic fluency, and naming of body parts did not take into account the phonemic transformations, which affected about half of the responses. Written naming was partially preserved, but the patient produced frequent letter errors and written neologisms. Comprehension of complex written sentences was impaired, whereas comprehension of single written words was good. Additionally, the patient was asked to name the 26 letters of the alphabet presented in random order. He made only one error, reading $\mathrm{R}$ as D.

The patient seemed quite unaware of most of his speech errors. He sometimes complained that he had made an error although his response was actually correct. Conversely, he was sometimes quite satisfied with grossly erroneous productions. For instance, when asked to name a locker ("cadenas" /kadna/ in French), he said "the /fobœnwa/! ha! I was looking for that word since yesterday".

We observed that a given word was sometimes produced correctly, and sometimes subject to phonological transformations. For instance, when asked to read aloud the word "tortue"/torty/ (tortoise), the patient said "la /torpi/ . . . un /amid3 / qui va dans les jardins, dans les jardins il y a des tortues (the/torpi/, an /amid3 / which goes in the gardens, there are tortoises in the gardens)". In order to document further this variability, a set of 10 pictures was presented to the patient 10 times for oral naming, each time in a different order. All 10 words 

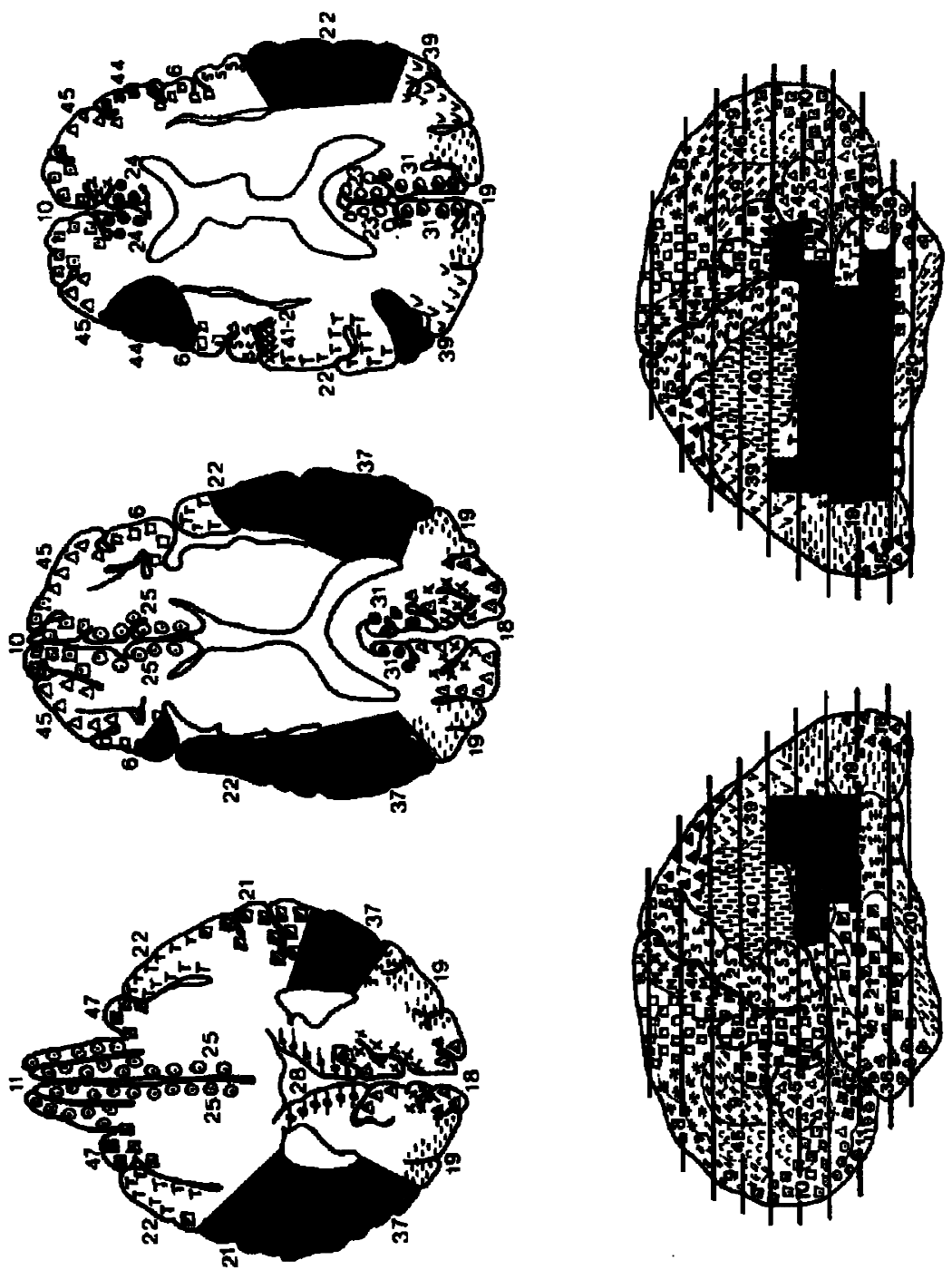

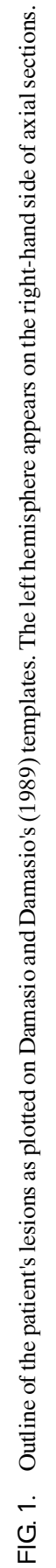


TABLE 1

Boston Diagnostic Aphasia Examination

\begin{tabular}{lc}
\hline Subtest & Score \\
\hline Fluency & \\
Articulation rating & $7 / 7$ \\
Phrase length & $7 / 7$ \\
Automatic speech & \\
Reciting & $1 / 2$ \\
Repetition & \\
Words & $0 / 10$ \\
High-probability sentences & $0 / 8$ \\
Low-probability sentences & $0 / 8$ \\
Writing & \\
Mechanics & $2 / 3$ \\
Serial writing & $47 / 47$ \\
Written confrontation naming & $8 / 10$ \\
Narrative writing & $2 / 4$ \\
Auditory comprehension & \\
Body-part identification & $0 / 20$ \\
Word discrimination & $0 / 72$ \\
Commands & $0 / 15$ \\
Complex ideational material & $0 / 12$ \\
Naming & \\
Naming of body-parts & $30 / 30$ \\
Confrontation naming & $65 / 105$ \\
Semantic fluency (animals) & $20 / 23$ \\
Reading & \\
Word reading & $30 / 30$ \\
Sentence reading & $0 / 10$ \\
Reading comprehension & $10 / 10$ \\
Word-picture matching & $5 / 10$ \\
Sentences and paragraphs & $9 / 10$ \\
Symbol discrimination & \\
\hline
\end{tabular}

were produced correctly at least once, but were also transformed at least once. For instance, the picture of a butterfly ("papillon" /papij / in French) was

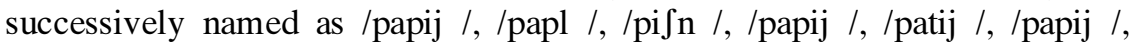
/papij /, / atij /, / apilj /,/pipal /.

\section{Comprehension of Written Words}

In order to test the comprehension of written words, the patient was simultaneously presented with 42 pictures selected from the line drawings in Snodgrass and Vanderwart (1980). He was then presented successively with the written names corresponding to 21 out of the 42 pictures, and was asked to match each name with the corresponding drawing. He responded rapidly and flawlessly. He would often produce naming errors at the same time as he was 
pointing to the correct picture. For instance, the patient said /alugre/ instead of "araignée" /arene/, and /zarkan/ instead of "raquette"/raket/, while correctly pointing to the pictures of a spider and of a racquet, respectively. In a further test of word comprehension, the patient could rapidly and flawlessly classify 25 written words into 5 semantic categories (furnitures, sports, animals, flowers, trees), despite frequent naming errors. These findings confirmed that the comprehension of single written words was intact.

\section{Auditory Perception of Nonverbal Stimuli}

In order to assess the auditory deficit beyond the domain of speech perception, the patient was presented with a series of 17 typical noises (e.g. ringing, mooing, etc), which he was asked to match with the corresponding pictures (e.g. a bell, a cow, etc). He succeeded on only 9/17 trials. When presented with popular tunes, he perceived them as music, but was unable to name them, or to choose among several written titles. Thus, as suggested by clinical examination, the perceptual deficit extended to nonlinguistic sounds.

\section{Summary}

In brief, the patient suffered from Wernicke's aphasia with neologistic jargon, in good agreement with the localisation of his left posterior superior temporal lesion (Naeser, Helm-Estabroks, Haas, Auerbach, \& Srinivasan, 1987). The association of right and left superior temporal lesions was probably responsible for the additional extension of the auditory deficit beyond the linguistic domain, verging on cortical deafness. In the following section, we will try to locate, within the speech production system, the mechanisms underlying the jargon. Since the patient was unable to process auditory stimuli, but understood pictures and written words normally, we used only reading aloud and picture naming tasks.

\section{EXPLORATION OF THE JARGON}

Before presenting experimental data, it may be useful to sketch an outline of the functional organisation of the speech production system (for reviews, see Levelt, 1989, 1992). Let us consider first the successive stages that lead from the perception of a picture to the production of the corresponding name (Fig. 2 ). Visual analysis of the picture of a cat results in the activation of the concept of cat. Access to this conceptual level consists in the retrieval of semantic information (animal, chases mice, etc). It is then possible to select the word "cat" and to retrieve lexical information about this word. There is evidence that such lexical knowledge becomes available in two successive steps. At a first stage, activation of the so-called word lemma gives access to syntactic characteristics such as grammatical class and gender (Badecker, Miozzo, \& Zanuttini, 


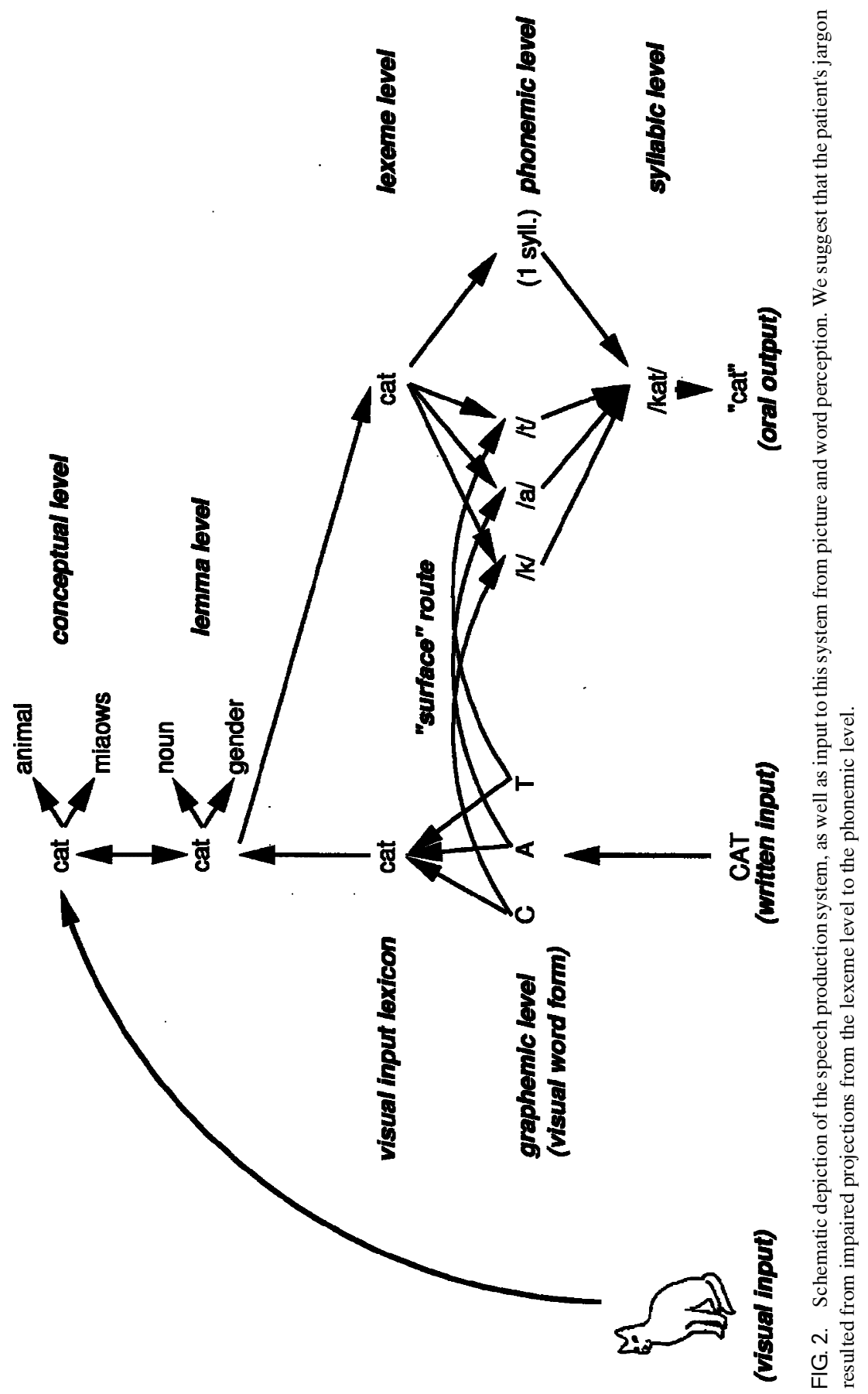


1995; Schriefers, Meyer, \& Levelt, 1990). The lemma may be viewed as the most abstract representation of the word, and constitutes a convergence hub to and from stored word forms in various modalities: auditory and visual input lexicons, phonological and orthographic output lexicons.

Access to the phonological output lexicon constitutes the second stage of lexical access during word production. It consists in activating the so-called word lexeme, that is the phonological features of the word that are necessary for oral output. Lexemes may be themselves broken down into two distinct types of information: (1) the segmental composition of the word (e.g. the phonemes $/ \mathrm{k} /, / \mathrm{a} /$, and $/ \mathrm{t} /$ ), and (2) its metrical structure, including in particular the number of syllables and possibly the consonant-vowel structure (Levelt, 1992; Sevald, Dell, \& Cole, 1995). The idea that segments and the structure are both stored, although as separate records, is supported by evidence from the study of spontaneous or elicited speech errors (e.g. Meyer, 1992; ShattuckHufnagel, 1979; Treiman, 1983), as well as from recent on-line studies of speech production (e.g. Sevald et al., 1995). Eventually, the phonemic and structural descriptions are combined, giving access to the corresponding syllables (e.g. /kat/) that constitute the building blocks of the articulatory program (Levelt \& Wheeldon, 1994).

Written words can be read aloud in a similar fashion through a lexical route. Following processing of their constituent graphemes, words are identified in the visual input lexicon, giving access to the corresponding lemma, and thence to the subsequent stages of verbal output. Words can also be read aloud through a so-called surface, nonlexical, route. This route maps any orthographically legal letter string into the corresponding sequence of phonemes, based on language-specific statistical regularities. This surface route is essential for naming nonwords, which by definition have no stored semantic or lexical representations.

Speech errors may result from dysfunctions affecting any one of these many processing stages. Leaving aside purely articulatory processes, the translation from the conceptual level to oral output may be subject to two main sources of error. First, faulty access to the lemma or lexeme levels may result in wordfinding difficulties or in the selection of inappropriate words. Second, impaired processing at the phonemic or syllabic levels may result in phonological transformations of the targets, resulting in phonological jargon. Needless to say, both mechanisms may be combined within a single trial, resulting in phonological transformations of an incorrectly selected word (Butterworth, 1979).

\section{Method}

Over several testing sessions, the patient was asked to name a total of 192 pictures of simple objects from various semantic categories, selected from the 
line drawings in Snodgrass and Vanderwart (1980), and to read aloud 502 words and 192 nonwords. Words were varied in frequency, length, imageability, and grammatical class.

Frequency and imageability ratings were taken from the BRULEX French lexical database (Content, Mousty, \& Radeau, 1990). Frequency was measured by the $\log _{10}$ of the number of occurrences by million. The targets of the picture naming task were all nouns. Nouns also constituted a large majority of the word reading material $(84.0 \%)$, whereas verbs, adjectives, and closed-class words represented $3.5 \%, 7.7 \%$, and $4.8 \%$ of targets, respectively. All nonwords were orthographically and phonologically legal letter strings. Targets are further described in terms of frequency, length, and lexical neighbourhood in Table 2.

The patient's responses were transcribed by the examiner, and tape-recorded for subsequent checking of the transcription. When the patient produced several responses to a given stimulus, which occurred exceptionally, only the first one was considered. The following analyses were run on phonetic transcriptions of the targets and responses.

\section{General Distribution of Errors}

In agreement with clinical observations, the patient produced only phonologically and phonetically well-formed answers. This allowed for a simple classification of responses into four exclusive categories: correct responses, absence

\section{TABLE 2}

Description of the Target Words and Nonwords Used in Naming Tasks

\begin{tabular}{|c|c|c|c|c|}
\hline & Mean & $S D$ & Min & $\operatorname{Max}$ \\
\hline \multicolumn{5}{|l|}{ Pictures $(N=192)$} \\
\hline Frequency $^{a}(N=178)$ & 1.11 & 0.78 & -1.1 & 2.95 \\
\hline Number of phonemes & 4.56 & 1.74 & 2.0 & 12.00 \\
\hline Number of syllables & 1.84 & 0.82 & 1.0 & 5.00 \\
\hline Number of neighbours ${ }^{b}$ & 111.80 & 122.9 & 0.0 & 434.00 \\
\hline \multicolumn{5}{|l|}{ Words $(N=502)$} \\
\hline Frequency $^{a}(N=480)$ & 1.51 & 0.94 & -1.1 & 3.81 \\
\hline Number of phonemes & 4.82 & 2.07 & 1.0 & 13.00 \\
\hline Number of syllables & 2.03 & 1.01 & 1.0 & 5.00 \\
\hline Number of neighbours ${ }^{b}$ & 110.00 & 122.9 & 0.0 & 434.00 \\
\hline \multicolumn{5}{|l|}{ Nonwords $(N=192)$} \\
\hline Number of phonemes & 4.29 & 1.71 & 2.0 & 11.00 \\
\hline Number of syllables & 1.72 & 0.86 & 1.0 & 4.00 \\
\hline Number of neighbours $^{b}$ & 104.00 & 92.60 & 0.0 & 432.00 \\
\hline
\end{tabular}

${ }^{a} \log _{10}$ of the frequency per million.

${ }^{b}$ Number of words of the same length differing by one or two phonemes. 
of response, verbal errors, and neologisms. Verbal errors and neologisms consisted of inappropriate words and nonwords, respectively.

\section{Overview of the Results}

The patient made a total of 630/886 (71.1\%) errors. As shown in Table 3, the error rate did not differ significantly across the three types of stimuli $\left[\chi^{2}(2)\right.$ $=5.04, P=.08]$. In all three tasks, neologisms were the most frequent type of response $(522 / 886,58.9 \%)$, and by far the most frequent type of error $(522 / 630$, $82.9 \%$ ). Furthermore, as illustrated in Table 4, a number of verbal errors probably resulted from phonemic errors accidentally producing real words (e.g. the picture of a fox was named as /rœtar/ [delay] instead of /rœnar/). Thus, phonemic errors were even more pervasive than the rate of neologisms would

TABLE 3

Distribution of Error Types

\begin{tabular}{|c|c|c|c|}
\hline & \multicolumn{3}{|c|}{ Entire Corpus } \\
\hline & $\begin{array}{c}\text { Pictures } \\
(N=192)\end{array}$ & $\begin{array}{c}\text { Words } \\
(N=502)\end{array}$ & $\begin{array}{l}\text { Nonwords } \\
(N=192)\end{array}$ \\
\hline Correct responses & $66(34.4)$ & $131(26.1)$ & $59(30.7)$ \\
\hline Errors & $126(65.6)$ & $371(73.9)$ & $133(69.3)$ \\
\hline No response & $9(7.1)$ & $6 \quad(1.6)$ & $1 \quad(0.8)$ \\
\hline Verbal paraphasia & $21(16.7)$ & $56(15.1)$ & $15(11.3)$ \\
\hline \multirow[t]{3}{*}{ Neologistic error } & $96(76.2)$ & $309(83.3)$ & $117(88.0)$ \\
\hline & \multicolumn{2}{|c|}{$\begin{array}{c}\text { Matched Pictures } \\
\text { and Words }\end{array}$} & \\
\hline & $\begin{array}{l}\text { Pictures } \\
(N=88)\end{array}$ & $\begin{array}{c}\text { Words } \\
(N=88)\end{array}$ & \\
\hline Correct responses & $31(35.2)$ & $22(25.0)$ & \\
\hline Errors & $57(64.8)$ & $66(75.0)$ & \\
\hline No response & 1 (1.8) & $\begin{array}{ll}0 & (0.0)\end{array}$ & \\
\hline Verbal paraphasia & $13(22.8)$ & $11(16.7)$ & \\
\hline \multirow[t]{3}{*}{ Neologistic error } & $43(75.4)$ & $55(83.3)$ & \\
\hline & & \multicolumn{2}{|c|}{$\begin{array}{l}\text { Matched Words } \\
\text { and Nonwords }\end{array}$} \\
\hline & & $\begin{array}{c}\text { Words } \\
(N=192)\end{array}$ & $\begin{array}{l}\text { Nonwords } \\
(N=192)\end{array}$ \\
\hline Correct responses & & $73(38.0)$ & $59(30.7)$ \\
\hline Errors & & $119(62.0)$ & $133(69.3)$ \\
\hline No response & & $1 \quad(0.8)$ & $1 \quad(0.8)$ \\
\hline Verbal paraphasia & & $26(21.8)$ & $15(11.3)$ \\
\hline Neologistic error & & $92(77.3)$ & $117(88.0)$ \\
\hline
\end{tabular}


TABLE 4

Examples of Verbal Errors Phonologically Close to the Target

\begin{tabular}{llll}
\hline & Stimulus & Target & \multicolumn{1}{c}{ Error } \\
\hline Picture & fox & /rœnar/ & /rœtar/ (delay) \\
Word & boîte (box) & $/$ bwat/ & /pwr̃t/ (tip) \\
Nonword & ulore & $/$ ylor/ & /alor/ (then) \\
\hline
\end{tabular}

suggest. This issue will be further discussed in the section devoted to verbal errors.

Comparison of the patient's behaviour with the different types of stimuli may have important bearings on the functional interpretation of the deficit. We therefore performed comparisons restricted to matched subsets of the stimuli. Picture naming and word naming were compared over a set of 88 nouns that were used in both tasks (Table 3 ). There was no difference in error rate $\left[\chi^{2}(1)\right.$ $=1.73, P=.19]$, nor in the distribution of error types $\left[\chi^{2}(2)=1.99, P=.37\right]$. We may note that with the $46 / 88$ words that were produced incorrectly in both tasks, the two errors were always different. Word reading and nonword reading were similarly compared over a set of 192 words and 192 nonwords matched for syllabic length (see Table 3 ). There was again no significant difference in error rate $\left[\chi^{2}(1)=1.95, P=.16\right]$, nor in the distribution of error types $\left[\chi^{2}(2)=\right.$ $5.18, P=.08]$.

\section{Length}

We expected a priori that the longer a target, the more numerous the phonological transformations that it would suffer. Indeed, error rate was significantly correlated with length, as measured by the number of phonemes $[r(884)=.31, P<.00001]^{1}$. This correlation prevailed across pictures $[r(190)$ $=.23, P=.0014]$, words $[r(500)=.34, P<.00001]$, and nonwords $[r(190)=$ $.29, P=.00004]$.

\section{Number of Lexical Neighbours}

Phonological transformations can occasionally result in the production of a real word. All targets are not equally exposed to this phenomenon. For instance, changing one phoneme of the french word /bal/ (or of the nonword $/ \mathrm{nal} /$ ) is

\footnotetext{
${ }^{1}$ The curve of error rate as a function of length was well fitted by a cumulative binomial function $\left[\chi^{2}(12)=10.4, P=.58\right]$, as may be expected assuming that the error probability on a given item roughly reflected the probability of independent errors on each phoneme.
} 
likely to result in a real word, such as $/ \mathrm{cal} /, / \mathrm{dal} /, / \mathrm{gal} /, / \mathrm{mal} /, / \mathrm{pal} /, / \mathrm{sal} /$, and many others, whereas changing one phoneme of the word "manivelle" /manivel/won' t yield a single real word. We therefore expected that the relative proportion of errors resulting in a real word would be higher the larger the number of neighbours. We computed the number of neighbours for all targets in the corpus. Neighbours were operationally defined as words comprising the same number of phonemes as the target, and differing from it by one or two phonemes. As expected, the relative proportion of verbal errors was significantly correlated with the number of neighbours $[r(628)=.39, P<.00001]$. This correlation prevailed across pictures $[r(124)=.27, P=.0024]$, words $[r(369)=.44, P<.00001$, and nonwords $[r(131)=.33, P=.00011]$.

We thus found that length and lexical neighbourhood had the expected influence on the overall error rate and on the relative rate of verbal errors, respectively. We then examined the influence of other possibly relevant parameters, for which we had no a priori expectancies: frequency, imageability, and grammatical class.

\section{Frequency}

We studied the influence of word frequency on the pattern of errors during picture naming and word reading. This analysis was restricted to 178 picture trials and 480 word trials for which a frequency rating was available (Content et al., 1990).

Error rate was significantly lower the higher the frequency $[r(656)=-.15$, $P=.00016]$. However, frequency was strongly correlated with length: the longer a word the lower its frequency $[r(656)=-.37, P<.0001]$. The apparent frequency effect could thus be an artefact of the length effect described earlier. In order to clarify this point, we examined whether any frequency effect would persist when keeping length constant. The effect of frequency was thus studied separately for words of $3,4,5$, and 6 phonemes $(N=155,173,102$, and 66 , respectively). Words shorter than three or longer than six phonemes were few, and insufficiently distributed across the frequency range to be relevant in this analysis. There was no significant correlation for any of the length classes (all $P<.13$ ). Thus, when keeping length constant, the overall error rate did not vary with frequency.

The relative proportion of verbal errors was also correlated with frequency $[r(461)=.24, P<.0001]$. However, frequency was strongly correlated with the number of neighbours $[r(461)=.37, P<.0001]$. We therefore looked to see if any frequency effect would persist when keeping the number of neighbours approximately constant. The 463 error trials were divided into 4 quartiles depending on the number of lexical neighbours of the target word, and the effect of frequency on the relative rate of verbal errors was studied separately for the 4 quartiles. There was no significant correlation for any of the neighbourhood 
classes (all $P>.10$ ). Thus, when keeping neighbourhood size constant, the relative rate of verbal errors did not vary with frequency.

\section{Imageability}

We studied the influence of word imageability on the pattern of errors during word reading. This analysis was restricted to 214 trials for which an imageability rating was available (Content et al., 1990).

There was no significant difference of overall error rate $\left[\chi^{2}(1)=1.43, P=\right.$ .23] nor of relative proportion of verbal errors $\left[\chi^{2}(1)=2.3, P=.13\right]$ between high- and low-imageability words $(\mathrm{N}=100$ and 114 , respectively).

\section{Grammatical Class}

The relatively small numbers of items in grammatical categories other than nouns make detailed comparisons difficult. However, post hoc analyses using $\chi^{2}$ tests revealed no significant differences in error rate, and no significant differences in the relative proportions of verbal errors and neologisms, when comparing closed-class with open-class words, and when comparing the three types of open-class words (i.e. nouns, adjectives, and verbs) among them (all $P>$.14). Similar analyses were performed on a controlled subset of the material comprising 28 open-class and 28 closed-class words matched for length and frequency (Segui, Mehler, Frauenfelder, \& Morton, 1982). There were again no differences between open- and closed-class words (all $P>.17$ ).

\section{Summary}

Word reading, nonword reading, and picture naming yielded a similar pattern of errors, with a massive predominance of neologisms. Longer targets produced more errors, whereas the number of lexical neighbours was a good predictor of the occurrence of verbal errors. No significant influence of frequency, imageability, or grammatical class was found.

\section{Phonological Features of Neologisms}

As mentioned in the clinical description, neologisms covered the whole range from single phoneme substitutions to neologisms very remote from the target (Table 5). However, we observed that even the most abstruse neologisms often had some similarity with the target word. Even when a majority of phonemes were transformed, the similarity was still apparent in terms of overall length and syllabic structure. This informal observation was evaluated by post hoc analyses of the corpus of 522 neologisms. 
TABLE 5

Examples of Neologisms

\begin{tabular}{|c|c|c|c|}
\hline & Stimulus & Target & Error \\
\hline \multicolumn{4}{|c|}{ Phonologically close $^{\mathrm{a}}$} \\
\hline Picture & necklace & /kolje/ & /kalje/ \\
\hline Word & étoile (star) & /etwal/ & /etwan/ \\
\hline Nonword & tomu & /tomy/ & /comy/ \\
\hline \multicolumn{4}{|c|}{ Phonologically remoteb } \\
\hline Picture & accordion & /akorde / & /bormeg / \\
\hline Word & toiture (roof) & /twatyr/ & /p pyl/ \\
\hline Nonword & molitude & /molityd/ & /polit d/ \\
\hline
\end{tabular}

${ }^{a}$ Neologisms phonologically close to the target.

${ }^{b}$ Neologisms phonologically remote from the target.

\section{Phonological Frame}

Number of syllables. Targets and neologisms were strongly correlated in terms of number of syllables $[r(520)=.87, P<.0001]$. As many as $413 / 522$ (79.1\%) neologisms had exactly the same number of syllables as the corresponding targets, while 100/522 (19.2\%) differed by 1 syllable, and only $9 / 522(1.7 \%)$ by 2 syllables. Table 6 shows the distribution of neologistic errors as a function of the length of the target and of the error. A similar correlation between targets and neologisms prevailed with pictures, words, and nonwords (all $P<.0001$ ). Analyses restricted to the matched subsets of stimuli described earlier indicated that the proportion of neologisms with a correct number of syllables was not different when naming pictures as compared to words $\left[67.4 \%\right.$ vs. $\left.81.8 \%, \chi^{2}(1)=2.70, P=.10\right]$, and when naming words as compared to nonwords [ $80.4 \%$ vs. $\left.88.9 \%, \chi^{2}(1)=2.91, P=.09\right]$. In brief, about $80 \%$ of neologisms had a correct number of syllables, whatever the type of stimuli.

TABLE 6

Preservation of the Number of Syllables in Neologisms

\begin{tabular}{lrrrrrrr}
\hline Target & 1 & 2 & 3 & 4 & 5 & 6 & Total \\
\hline 1 & 99 & 32 & 3 & & & & 134 \\
2 & 5 & 180 & 21 & 1 & & & 207 \\
3 & & 9 & 84 & 11 & 2 & & 106 \\
4 & & & 21 & 49 & & 1 & 71 \\
5 & & & 2 & 1 & 1 & & 4 \\
6 & & & & & & & 0 \\
Total & 104 & 221 & 131 & 62 & 3 & 1 & 522 \\
\hline
\end{tabular}


Syllabic structure. In order to study the transformation of syllabic structures, we analysed the corpus of 912 syllables corresponding to the 413 trials on which target and neologism had the same number of syllables (see Table 7). Note that 224 of these neologisms (54.2\%) not only had the same number of syllables as the target, but were entirely correct in terms of alternation of consonants and vowels. Syllabic structure was preserved in 685/912 (75.1\%) syllables. The preservation of syllabic structure was not restricted to the simplest and most frequent $\mathrm{CV}$ and $\mathrm{CVC}$ structures (e.g. a belt was named

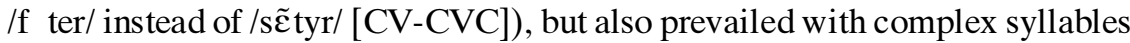
with consonant clusters, even when most phonemes were erroneous. For instance the word "livre" (book) was read as /pert/ instead of /livr/ (CVCC), and the word "norme" (norm) was read as /diln/ instead of /norm/ (CVCC).

Analyses restricted to the matched subsets of stimuli indicated that syllabic structure was preserved somewhat more often for words as compared to pictures $\left[83.5 \%\right.$ vs. $\left.67.9 \%, \chi^{2}(1)=4.88, P=.027\right]$, whereas there was no difference between words and nonwords $\left[74.5 \%\right.$ vs. $80.4 \%, \chi^{2}(1)=1.74, P=$ .19].

We observed that whenever the patient produced an erroneous syllabic structure, he often selected syllabic structures that are frequent in French, and more rarely syllabic structures that are infrequent in French. There was thus a strong correlation between the frequency of the various syllabic structures in the language and in the patient's errors $[r(11)=.98, P<.0001]^{2}$. For instance, CV and CVC syllables, which are very frequent in French $(50.1 \%$ and $19.5 \%$ of syllables in our corpus of target words), constituted as much as $47.1 \%$ and $24.1 \%$ of the erroneous structures produced by the patient.

TABLE 7

Preservation of Syllabic Structure in Neologisms

\begin{tabular}{|c|c|c|c|c|c|c|c|c|c|}
\hline \multirow[b]{2}{*}{ Target } & \multicolumn{9}{|c|}{ Response } \\
\hline & $C V$ & $C V C$ & V & $C Y V$ & $C C V$ & $C C V C$ & $C V C C$ & Other & Total \\
\hline $\mathrm{CV}$ & 393 & 34 & 4 & 16 & 7 & & & 3 & 457 \\
\hline $\mathrm{CVC}$ & 37 & 127 & & 3 & 3 & 2 & 4 & 2 & 178 \\
\hline V & 16 & & 58 & & 1 & & & 3 & 78 \\
\hline CYV & 25 & 2 & & 21 & & & & 2 & 50 \\
\hline $\mathrm{CCV}$ & 20 & 1 & & 2 & 24 & 2 & & & 49 \\
\hline CCVC & & 2 & & & 1 & 18 & 1 & 1 & 23 \\
\hline CVCC & & 4 & & & 1 & & 16 & 2 & 23 \\
\hline Others & 9 & 11 & 3 & & 1 & & 2 & 28 & 54 \\
\hline Total & 500 & 181 & 65 & 42 & 38 & 22 & 23 & 41 & \\
\hline
\end{tabular}

${ }^{2}$ In this analysis, the frequencies of the various syllabic structures in French were estimated on the basis of the corpus of target words. 


\section{Phonemic Content}

In order to identify factors governing phoneme substitutions, we analysed the set of 224 neologistic errors on which the syllabic structure of the whole word was preserved. A total of 561/1068 (52.5\%) phonemes were correct. The same analysis performed with the matched subsets of stimuli showed that the proportion of correct phonemes did not differ between pictures and words (50.8\% vs. $50.7 \%$ ), nor between words and nonwords (50.0\% vs. $55.5 \%$ ).

There was no tendency for consonants to be substituted by consonants of the same type (Table 8). When selecting an inappropriate consonant, the patient showed a decreasing preference for stops, fricatives, liquids, and nasals, irrespective of the type of target consonant $\left[\chi^{2}(9)=8.36, P=.50\right]$. This systematic bias closely followed the frequency distribution of consonant types in the language, as reflected in the composition of the corpus $[r(2)=.972, P=.028]$.

As with consonants, no systematic relationship was found between target and response vowels. The patient showed an idiosyncratic preference for nasal vowels $(/ /, / /, / \tilde{\varepsilon} /)$, which represented $18.6 \%$ of target vowels but as much as $40.3 \%$ of vowel substitutions. He also tended to avoid high vowels $(/ \mathrm{i} /, / \mathrm{y} /, / \mathrm{u} /)$, which represented $30.9 \%$ of target vowels but only $14.1 \%$ of vowel substitutions.

Finally, we observed occasional perseverations of a given phoneme over a series of consecutive trials. For instance, while the patient was reading aloud a list including words and nonwords, the phoneme /d/ was erroneously produced in 27 out of 38 consecutive trials, associated with a variety of vowels and syllabic structures.

\section{Summary}

These analyses clearly confirmed the informal observation that neologisms were phonologically related to the corresponding targets. In particular, even when the phonemic composition of neologisms was grossly incorrect, the overall phonological frame, as measured by the number of syllables and the CVC structure, was generally preserved. We also noted that the selection of

TABLE 8

Substitutions of Consonant Types in Neologisms

\begin{tabular}{lccccc}
\hline \multicolumn{5}{c}{ Response } \\
\cline { 2 - 6 } Target & Stops & Fricat & Liquids & Nasals & Total \\
\hline stops & 57 & 32 & 18 & 13 & 120 \\
fricatives & 35 & 25 & 16 & 7 & 83 \\
liquids & 26 & 20 & 9 & 13 & 68 \\
nasals & 18 & 8 & 8 & 8 & 42 \\
Total & 136 & 85 & 51 & 41 & 313 \\
\hline
\end{tabular}


erroneous consonants and erroneous syllable structures followed the frequency distributions of the French language. This amounts to saying that the patient selected erroneous consonants and syllable structures randomly, but still reflecting French statistical regularities.

\section{Verbal Errors}

In an attempt to characterise the patient's phonological encoding impairment on as well defined an empirical basis as possible, neologisms were analysed separately, and verbal errors put aside. However, there is evidence that verbal errors resulted from exactly the same phonological encoding deficit as neologisms. This hypothesis is already supported by the correlation between the rate of verbal errors and the number of lexical neighbours of the targets. Furthermore, on informal inspection, verbal errors were often phonologically close to the targets (Table 7). In order to confirm this impression we resorted to more formal analyses, and showed that verbal errors had exactly the same degree of phonological proximity to the targets as did neologisms:

1. Targets and verbal errors were highly correlated in their number of syllables $[r(90)=.71, P<.0001]$. The percentage of errors with a correct number of syllables was as high with verbal errors as with neologisms [78/92 $(84.8 \%)$ vs. $\left.413 / 522(79.1 \%), \chi^{2}(1)=1.57, P=.21\right]$.

2. The percentage of errors in which the syllabic structure of the target was fully preserved was not different with verbal errors and with neologisms [45/92 (48.9\%) vs. $\left.224 / 522(42.9 \%), \chi^{2}(1)=1.14, P=.28\right]$.

3 . The percentage of correct phonemes in errors preserving syllabic structure was not different with verbal errors and with neologisms [73/151 (48.3\%) vs. $\left.561 / 1068(52.5 \%), \chi^{2}(1)=.93, P=.34\right]$.

This suggests that the distinction we made between neologisms and verbal errors was simply descriptive and did not reflect distinct pathophysiological mechanisms (for discussion of a contrasting case, see Best, 1996).

\section{Discussion of the Jargon}

The data clarify the functional localisation of the patient's impairment within the speech production system. The fact that there was no effect of imageability, lexical status (word or nonword), frequency, or grammatical word class on error rates suggests a low-level impairment. We have also seen that the pattern of errors was similar with pictures, words, and nonwords. This suggests that errors originated downstream from the point of convergence of the three tasks. The most straightforward account would be a deficit in activating phonemes, at a relatively late stage of speech planning common to all types of targets (see General Discussion). 
The analysis did, however, reveal some subtle differences between picture naming and reading: the phonological similarity between targets and neologisms was slightly weaker with pictures than with written words $(67.4 \%$ vs. $81.8 \%$ of neologisms with a correct number of syllables, $67.9 \%$ vs. $82.4 \%$ of syllables with a correct structure). This finding can be readily explained by the existence of two routes for word reading. During word reading, the phonemic output is conditioned both by the surface route that maps graphemes into phonemes, and by the "deep" reading route in which phonemes are activated from lexeme nodes. In contrast, the surface route is not involved in picture naming. The phonemic output is therefore less constrained, and expected to differ more widely from the expected target, during picture naming than during word reading.

Did the patient also suffer from an additional impairment of word selection? Although it is possible that some neologisms resulted from phonological transformations affecting inappropriate words, we found little positive evidence for such word selection difficulties. Word substitutions in aphasic patients often result in semantically related responses (Kohn \& Goodglass, 1985). Here, however, most verbal errors could be explained by neighbourhood effects in which the random substitution of a phoneme in a short word is likely to result in the production of another word rather than a neologism. A plausible meaning relationship between the target word and the patient's response was discernible for only 12/92 verbal errors. Moreover, these 12 errors possibly included visual confusions between very similar objects in picture naming (e.g. shirt $\rightarrow$ coat; orange $\rightarrow$ apple; cloud $\rightarrow$ cake), as well as phonological transformations (e.g. a glove was named as /d $\tilde{\varepsilon} /$ [suede] instead of $/ \mathrm{g} /$ ). On the whole, whatever the mechanism underlying such ambiguous errors, errors imputable to semantic proximity were exceptional, contrary to what could be expected if the patient suffered from a significant impairment of word selection.

\section{EXPLORATION OF NUMBER PROCESSING}

During informal clinical evaluation, we observed that whenever the patient was reading arabic numerals aloud, his speech seemed free of phonemic errors. We felt that, if confirmed, this surprising observation could contribute to the understanding of the mechanism of the jargon, as well as reveal dissociations between distinct word categories within the speech production system. We will now turn to a study of the patient's performance in number processing tasks, and particularly in simple reading tasks requiring oral output of number names. 


\section{General Features}

\section{Reading Aloud Arabic Numerals}

The patient was asked to read aloud 470 arabic numerals from 1 to 6 digits long. The most striking observation was that his production was essentially free of all phonological errors ( 6 out of 470 trials; e.g. $18 \rightarrow / \mathrm{dez} /$ ), in sharp contrast with his usual speech production. All phonological errors are listed in Table 9. The patient made a total of 213/470 (45.3\%) errors, of which a large majority $(190 / 213,89.2 \%)$ consisted of legal numerals. Furthermore, these legal responses had generally the same length as the corresponding targets $(145 / 190$, $76.3 \%$ ): single digits were often read as single digits, two-digit numerals as two-digit numerals, etc. The remaining 23 errors included: the 6 phonological errors; 11 illegal numerals (e.g. $47 \rightarrow$ "fourteen seven"), some of which were probably self-corrections (e.g. $92 \rightarrow$ "quatre . . quatre-vingt douze"); 4 transformations into multiplication problems (e.g. $94 \rightarrow$ "nine times four"); and 2 failures to respond.

The mechanisms that allow one to transcode arabic numerals into strings of words may be broken down into two separate subprocesses. (1) The generation of a word frame that specifies the sequence of word classes to produce. For example, the word frame for 235 would be, stated informally, "a ones word followed by 'hundred', then a tens word and finally a ones word". (2) The retrieval of the appropriate words within the specified classes, on the basis of the identity of digits (e.g. $2 \rightarrow$ «two», $3 \rightarrow$ «thirty», etc). There is good neuropsychological evidence that the generation of the word frame and the selection of specific words can be impaired independently from one another, yielding respectively frame (or syntactic) errors (e.g. $54 \rightarrow$ "five hundred and

TABLE 9

List of All Phonological Errors in Number Reading

\begin{tabular}{lll}
\hline & \multicolumn{1}{c}{ Target } & \multicolumn{1}{c}{ Error } \\
\hline Arabic numerals & 62 & $/ \mathrm{kuz} / \mathrm{deux}$ \\
$(N=470)$ & 74 & $/ \mathrm{kl} \tilde{\varepsilon} \mathrm{fo} /$ \\
& 902 & $\mathrm{huit} / \mathrm{f} / \mathrm{deux}$ \\
& 18 & $/ \mathrm{dez} /$ \\
& 601 & $\mathrm{six} / \mathrm{mel} / \mathrm{treize}$ \\
& 421 & trois cent $/ \mathrm{d} \mathrm{z} /$ \\
& & \\
Spelled-out numerals & soixante quatorze & six $/ \mathrm{z} /$ quatorze \\
& trois cent cinq & quatre $/ \mathrm{ka} / \mathrm{cinq}$ \\
& soixante & $/ \mathrm{seks} \mathrm{t} /$ \\
& quarante & $/ \mathrm{twar} \mathrm{t} /$ \\
& quatorze & $/ \mathrm{kar} 3 /$ \\
& six mille treize & $\mathrm{six} / \mathrm{mel} / \mathrm{treize}$ \\
\hline
\end{tabular}


four") and lexical errors (54 $\rightarrow$ "fifty three") (Cohen \& Dehaene, 1991; McCloskey, Sokol, \& Goodman, 1986). The patient's 190 legal errors included both frequent frame errors (e.g. $74 \rightarrow 704)$ and frequent lexical errors (e.g. 250 $\rightarrow 460$ ), sometimes associated within a single trial (e.g. $687 \rightarrow 6714$ ), attesting the disruption of multiple components of the transcoding mechanisms.

\section{Reading Aloud Spelled-out Numerals}

The patient was asked to read aloud 197 spelled-out numerals from 1 to 7 words long. Just as in arabic number reading, a striking feature of his behaviour was the almost complete absence of phonological errors (6 out of 197 trials). For instance, "quarante" was read as/twar t/ instead of / kar t/. All phonological errors are listed in Table 9.

The patient made a total of 138/197 (70.1\%) errors. Almost all errors $(130 / 138,94.2 \%)$ consisted of phonologically well-formed number words. The remaining eight errors included six phonological errors and two transformations into multiplication problems (e.g. "quarante sept mille treize" $\rightarrow$ "sept fois cinq trente" [seven times five thirty]).

With numerals comprising several words, the patient resorted to a word-byword reading strategy, and therefore most errors $(104 / 130,80.0 \%)$ comprised the correct number of words. However, since he paid little attention to the general structure of the target, many responses formed illegal word strings. For instance, "mille neuf cent quatorze" (1914) was read as "huit quatre neuf quatorze" (eight four nine fourteen). French compound number words, such as "dix-neuf " or "quatre-ving t" were printed with no dash, and the patient treated the two components as independent words, as evidenced by the occurrence of errors such as "dix huit" (18) $\rightarrow$ "sept quinze" (seven fifteen). Considering the corpus of 104 error trials on which the number of words of the response was correct, we noted that the patient did not substitute words with other words from the same class, but showed a systematic response bias. He had a decreasing preference for ones words $(139 / 203,68.5 \%)$, teens words $(54 / 203,26.6 \%)$, and tens words $(4 / 203,2.0 \%)$. This pattern prevailed whatever the type of target, including multipliers "hundred" and "thousand".

Thus, when he was reading aloud arabic or spelled-out numerals, and in contrast with his ordinary behaviour, the patient's speech was free of phonological transformations. Nonetheless, he made frequent reading errors. In order to determine whether these reading errors resulted from an impaired comprehension of the stimuli, or from an impaired visual-to-verbal mapping, we then assessed the patient's comprehension of written numerals. 


\section{Number Comprehension}

Understanding meaningful arabic numerals. The list of arabic stimuli that the patient was asked to name, as reported before, included numerals with a special meaning, such as famous dates, brands of cars, etc. (Cohen, Dehaene, \& Verstichel, 1994). When naming such numerals, the patients would occasionally provide accurate semantic comments, even when reading aloud was erroneous. For instance, when presented with the numeral "1789", he said "1989, the French Revolution". With "1939", he said "1839, it's the war"; with "1515", he said "1815, Francis the First"; with "1918" he said "1418, the end of World War I"; with " 13 " he said "713, it brings luck". He never produced inappropriate comments with numerals carrying no such special meaning.

Magnitude comparison. In order to assess further the patient's comprehension of numbers, he was presented with 39 pairs of arabic numerals from 1 to 6 digits long (the two numerals in each pair had the same number of digits), and with 37 pairs of spelled-out numerals (the two numerals in each pair had the same number of words). The patient was asked simply to point to the larger numeral in each pair, but he often tried to name the stimuli at the same time.

He made $1 / 39$ (2.6\%) comparison errors with arabic numerals, and 2/37 (5.4\%) comparison errors with spelled-out numerals. This excellent performance contrasted with the numerous naming errors that the patient produced at the same time as he was readily pointing to the larger number. For instance, when presented with the pair "14 17", the patient read "2918" while correctly pointing to 17 . Similarly, "14 13" was read as "14 15", "50 40" as "50 60", "951 954" as "612 611", while the patient always pointed correctly to the larger numeral. The same phenomenon was observed with spelled-out numerals. Thus, the patient read "trente (30) cinquante (50)" as "17 16", while pointing to "cinquante". With numerals comprising several words, he occasionally uttered illegal word strings, as shown before, while at the same time comparing the two numerals correctly.

Calculation. The patient was presented visually with 24 arithmetic problems involving 1 - and 2-digit numerals (8 addition, 8 subtraction, and 8 multiplication problems), and was asked to write down the result. He made a total of 5/24 errors. He accurately solved relatively difficult problems such as $8 \times 7,50-34,8+27$ or $31+12$. It may be speculated that at least some calculation errors actually resulted from errors in transcoding the arabic operands into words (e.g. $2 \times 2 \rightarrow 8,8 \times 3 \rightarrow 12,8-3 \rightarrow 7$ ). For instance, the patient may covertly have read $8 \times 3$ as "four times three", hence retrieving the erroneous result "twelve" from arithmetic memory (Dehaene \& Cohen, 1997).

In order to test calculation abilities without requiring the overt production of any numerals, the patient was presented visually with 35 simple arithmetic 
problems (12 addition, 11 subtraction, and 12 multiplication problems). The proposed result was erroneous in 23 problems (e.g. $7 \times 6=40$ ), and the correct result in 12 problems (e.g. $6 \times 8=48$ ). The patient was asked to decide whether each problem was correct or false. He did not make a single error ${ }^{3}$.

In conclusion, the patient's good performance in this group of tasks tapping number comprehension demonstrates that he could understand arabic and spelled-out numerals much more accurately than suggested by his poor reading performance. As a consequence, we may conclude that naming errors resulted from an impaired selection of number words for verbal output on the basis of a correct analysis of the input.

\section{Discussion of Number Processing}

\section{The Absence of Phonological Errors in Number Reading}

The most striking feature of number reading was the almost complete absence of phonological errors. Could this dissociation be an artefact, reflecting some superficial and systematic difference between number words and other words? One possibility is that number words are generally high-frequency words, a feature that might account for their sparing by phonological transformations. This hypothesis does not seem very likely given that frequency had no influence on the rate of phonological errors in reading non-numerical words. Still, in order to evaluate it, we selected for each number word all the non-numerical trials with a target word that (1) had the same number of phonemes as the considered number word, and (2) had a strictly higher frequency. As is apparent from Table 10, those selected non-numerical words were subject to many neologistic errors, whereas, as shown before, the corresponding number words were essentially free of such errors ${ }^{4}$. This conservative analysis allows us to conclude that number words were not spared simply by virtue of their relatively high frequency. In fact, the only parameter that was found to have a significant influence on error rate during word reading is target

${ }^{3}$ The patient's relatively good performance on the verification task may seem to be at odds with our hypothesis (Dehaene \& Cohen, 1995, 1997) that the knowledge of arithmetic facts is partly based on a verbal coding of the operands. However, we explicitly postulate that only a limited subset of arithmetic facts are solved on the basis of verbal automatisms (mostly small multiplications and some additions). In the present case, we do not know exactly how the patient proceeded to verify the various types of problems. Since he was not asked to read aloud the operands and proposed result, it is also quite possible that he occasionally selected the correct answer by chance $(50 \%)$ or in spite of reading and/or calculation errors. At any rate, this good performance does by no means undermine our conclusion that the patient understood numerals satisfactorily.

${ }^{4}$ This analysis was performed omitting the number word "un" (one), which is identical to the undefinite article and is the most frequent single-phoneme word in French. 
TABLE 10

Neologisms with Non-numerical Words Matched with Number

Words

\begin{tabular}{lccc}
\hline Number Words & Frequency & $\begin{array}{c}\text { Number of } \\
\text { Matched Trials }^{\mathrm{b}}\end{array}$ & $\begin{array}{c}\text { Number of } \\
\text { Neologisms (\%) }\end{array}$ \\
\hline un & 4.13 & - & - \\
deux & 3.17 & 2 & $1(50.0)$ \\
trois & 2.73 & 7 & $1(14.3)$ \\
quatre & 2.44 & 20 & $7(35.0)$ \\
cinq & 2.34 & 34 & $10(29.4)$ \\
six & 2.15 & 44 & $14(31.8)$ \\
sept & 1.95 & 66 & $23(34.8)$ \\
huit & 2.11 & 47 & $16(34.0)$ \\
neuf & 2.13 & 44 & $14(31.8)$ \\
dix & 2.40 & 32 & $10(31.3)$ \\
onze & 1.50 & 32 & $9(28.1)$ \\
douze & 1.69 & 75 & $27(36.0)$ \\
treize & 1.18 & 109 & $51(46.8)$ \\
quatorze & 1.32 & 29 & $22(75.9)$ \\
quinze & 1.88 & 69 & $26(37.7)$ \\
seize & 1.29 & 104 & $37(35.6)$ \\
vingt & 2.32 & 13 & $2(15.4)$ \\
trente & 1.92 & 57 & $26(45.6)$ \\
quarante & 1.75 & 34 & $25(73.5)$ \\
cinquante & 1.81 & 32 & $24(75.0)$ \\
soixante & 1.55 & 23 & $18(78.3)$ \\
cent & 2.33 & 13 & $2(15.4)$ \\
mille & 2.32 & 35 & $10(28.6)$ \\
\hline
\end{tabular}

${ }^{a} \log _{10}$ of the frequency per million.

${ }^{b}$ Trials with target words (1) matched in length with the number word, and (2) higher in frequency than the number word.

length. Yet the length of number words ranges from one to seven phonemes, so this variable obviously cannot account for the total sparing of numbers.

Yet another possibility would be that the patient adopted a particular response strategy in the case of number words, due to the fact that number words form a small closed set. Whenever the phonological form of the target word would not be fully available, the patient would elect to produce another more accessible word from the same category. However, several observations suggest that this hypothesis is probably not correct. First, as noted in the clinical section, the patient was generally unaware of his phonological errors, and seemed quite satisfied with gross transformations of the targets. Why then would he always prefer to produce another number word, rather than the correct target plus some phonological transformations? Second, the patient's initial attempts at producing the correct target (i.e. before choosing to produce another number word) should be detectable as initial phonological errors (something 
like e.g. $3 \rightarrow$ bree ... glee ... four!). At the very least, assuming that these putative initial attempts were covert, the patient's responses should have been substantially delayed. Actually, the patient's errors were produced rapidly and without initial phonological errors. Third, it is not obvious why the patient would not apply the same strategy to non-numerical targets also. However this was not the case, as seen from the small number of verbal errors and the almost complete absence of semantic errors. A final argument against the existence of such a response strategy would be the immunity of number words in connected speech when they are intermingled with other words, a kind of data that, unfortunately, we did not gather (see footnote 5 for relevant examples).

Thus it seems safe to conclude that the sparing of number words did not result from some artefact, but reflected their status as a particular category, an issue that will be addressed in the General Discussion.

\section{The Origin of Number Reading Errors}

Although the patient made numerous errors in reading aloud arabic and spelled-out numerals, there was good evidence from number comparison and arithmetic verification tasks that he could comprehend these same numerals accurately. Therefore reading errors resulted from a specific impairment in mapping arabic or spelled-out stimuli to the corresponding words. With arabic numerals, errors affected both components of the mapping system: frame generation, resulting in syntactic errors such as $74 \rightarrow$ "seven hundred and four", and lexical retrieval, resulting in lexical errors such as $66 \rightarrow$ "fifty six". With spelled-out numerals, all errors could be considered as lexical, since the patient merely read word by word, seemingly building no word frame at all.

\section{GENERAL DISCUSSION}

\section{Summary}

We have reported the case of a patient with Wernicke's aphasia who suffered from severe neologistic jargon (for reviews and related cases, see Butterw orth, 1979, 1992; Ellis, Miller, \& Sin, 1983; Lecours, 1982). The neologisms, al though generally close to the target in terms of overall syllabic structure, were marred by pervasive phoneme substitutions. Word and nonword reading, as well as picture naming, were equally affected. Performance was not influenced by lexical variables such as frequency, imageability, or grammatical class. Remarkably, phonological errors were almost never observed when the patient read numerals. As mentioned in the Case Report, this sparing extended to the naming of isolated letters, although this category was much less thoroughly studied. When reading aloud arabic or spelled-out numerals, the patient's errors consisted of substituting an entire number word for another rather than selecting inappropriate phonemes. 
Number words and ordinary words thus displayed a double dissociation pattern. On the one hand, number words were subject to frequent word substitutions, but escaped phonological transformations. On the other hand, ordinary words were subject to pervasive phonological transformations, but escaped word substitution errors 5 . The two major components of the patient's deficit could be accounted for in some detail, each within the appropriate framework. We will now try to address the issues raised by the combination of the two deficits, and particularly by the intriguing fact that number words escaped phonological errors, an observation that current models of speech planning, which make no distinction between categories of words at the phonological level, are unable to account for.

\section{Origins of the Phonological Impairment}

The simple fact that a category of words was unaffected by phonological errors may provide insights about the functional origin of the jargon. Within current models of speech production (e.g. Levelt, 1989, 1992), two broad alternative origins are conceivable for the patient's phonological errors. Errors could occur when retrieving the sequence of phonemes corresponding to a given word, or they could occur when selecting syllables on the basis of a given string of phonemes. For instance, when trying to pronounce the word "année", an error such as /ane/ $\rightarrow$ / te/ could result either from the activation of phonemes / / and $/ \mathrm{t} /$ instead of phonemes $/ \mathrm{a} /$ and $/ \mathrm{n} /$, or, at a later stage, from the activation of syllables / / and /te/ instead of syllables /a/ and /ne/ (Levelt \& Wheeldon, 1994). Both accounts seem equally compatible with the good preservation of

${ }^{5}$ Following completion of this study, we discovered that in his classical 1965 article Disconnexion syndromes in animals and man, N. Geschwind gave a brief but pithy description of phenomena strikingly similar to those studied here, occurring in patients labeled as conduction aphasics (Geschwind, 1965, p. 627). He noticed that number words were spared by phonological errors, while they could be erroneously substituted by one another: "A remarkable feature of many of these cases is the frequently preserved ability of the patient to repeat polysyllabic numbers, e.g. seventy-eight, while he fails to repeat even shorter words, or repeats them paraphasically. (. . .) Even when these patients fail to repeat numbers correctly, their errors are different from those with words. Thus, the patient tends to substitute other numbers, but rarely to produce grossly paraphasic responses (...)". Geschwind provided nice examples of this dissociation within single utterances combining numerical and non-numerical words (e.g. fifty-five per cent $\rightarrow$ fifty-five progum; three quarters $\rightarrow$ three four; one half $\rightarrow$ fifty; three quarters $\rightarrow$ seventy five). Finally, while his discussion is mostly based on speech repetition data, Geschwind mentioned that "this advantage of numbers is not confined to the spoken modality since our first patient read printed words paraphasically, but read numbers aloud correctly whether printed as numerals or as words". Due to his major perceptual impairment, our patient was unable to repeat anything at all, but Geschwind's observations, by extending the dissociation to a task with an auditory input, further confirm that the dissociation between word categories indeed reflects the structure of the speech production system. 
the phonological frame, particularly of the number of syllables, in the patient's neologisms.

Both hypothes es, however, are not equally compatible with the sparing of number words. In connected speech, words of various syntactic and semantic categories can be uttered in succession without phonological discontinuity. In particular syllables may bridge over the boundaries of grammatical words, content words, number words, etc. For instance, the words "quatre"/katr/ (four) and "amis" /ami/ (friends) are syllabified as $/ \mathrm{ka} /-/ \mathrm{tra} /-/ \mathrm{mi} /$, where the syllable /tra/ combines phonemes / tr/ from the number word "quatre" and phoneme /a/ from the noun "amis". This indicates that such "resyllabification" cannot be a category-specific process. The retrieval of syllables from phonemes obviously spans across all word categories and does not take into account the particular words to which the individual phonemes belong. Hence, an impairment at the syllabic level should affect words of all types equally, including number words. The sparing of number words therefore argues strongly against an impairment of syllable retrieval (or of any subsequent process).

The hypothesis of an impaired activation of phonemes thus seems the only viable account of phonological errors. It may be interesting to remember that the phonological perseverations observed during the production of series of words consisted of the iteration of a given phoneme, and not of a given syllable. This observation further confirms that the phonological impairment affected phoneme selection rather than syllable selection.

Thus, the main interest of the present observation is that it reveals that some categorical organisation prevails in the speech production system, down to the remarkably peripheral level of phoneme selection. In our patient, the activation of phonemes from the lexemes of number words was intact, whereas the activation of the same phonemes from the lexemes of other words was impaired.

The dissociation of number words from other categories of words at the phonological level, though unexpected, is not without parallels in normal speech production. In French, the phenomenon of liaison also provides indications that number words and also letter names may be processed in a distinct way at the phoneme retrieval stage of speech production. In many words, the final consonant is not overtly realised in the speech output. When the initial phoneme of the following word is a vowel, however, this final consonant must be uttered in order to provide a link (liaison in French) to the following word. For instance, "gros" (fat) is pronounced /gro/, but "gros homme" (fat man) is pronounced /gro-zom/. Note that the added phoneme depends on the specific words to be produced: / $\mathrm{z} /$ in "gros homme" but /t/ in "grand homme" and /n/ in "bon homme". Hence, liaison occurs at the processing stage most relevant to the present work, namely the selection of phonemes appropriate to produce a given lexeme. A related phenomenon, known as epenthesis, consists of the suppression of the final vowel of clitic words when the following word begins with a vowel. For instance, one says "l' ami" (the friend) and not "le ami". 
Remarkably, there is no liaison and no epenthesis when the second word is a number word or a letter name. For instance, "les huitres" (the oysters) and "les oncles" (the uncles) are pronounced with liaison as /le-zuitr/ and /le-z kl/, whereas "les huit ..." (the eight ...) and "les onze ..." (the eleven ...) are pronounced as /le-uit/ and /le- z/. Similarly, "les airs, les oeufs, les ailes" (the airs, the eggs, the wings) is pronounced as /le-zer, le-zœ, le-zel/, but "les R, les E, les L" (the Rs, the Es, the Ls) as /le-er, le-œ, le-el/. There is obligatory epenthesis in "l'oncle" (the uncle) and "l' huissier" (the usher), whereas one rather says "le onzième" and "le huitième". Hence this observation indicates that in normal subjects, phoneme selection may be influenced by the category of the words to be pronounced, in agreement with the present observation that a deficit at this level can selectively spare the category of number words ${ }^{6}$.

Our finding of a peripheral yet category-specific deficit is also strikingly similar, in the spoken modality, to a phenomenon reported by Anderson, Damasio, and Damasio (1990) in the domain of written language. As a result of a small left frontal lesion, Anderson et al.'s patient suffered from severe alexia and agraphia. Both of these deficits spared entirely arabic numerals. One of the most remarkable features of this patient was the contrast between the illegible scribble resulting from her painful attempts at writing down letters, and her perfectly shaped and easily drawn arabic numerals. Since the graphomotor patterns required by letters and digits are of comparable complexity, this clear-cut dissociation suggested that the peripheral writing system may be controlled by separate and dissociable systems devoted to arabic digits vs. ordinary words. We draw a tentative parallel between such a sparing of "graphological encoding" of digits and the present sparing of phonological encoding of number words. Taken together, these results suggest that numbers activate the elementary building blocks of the corresponding spoken and arabic output forms through pathways functionally and anatomically distinct from other words.

\section{Why Are Numbers a Phonologically Relevant Category?}

We have shown that number words were not spared by virtue of some superficial difference from other words in terms of frequency, length, phonological complexity, etc. It also seems unlikely that numbers were spared because of their grammatical status. From a syntactic point of view, number words are akin both to adjectives and to common nouns (Hurford, 1987), two categories that

${ }^{6}$ There are other French words beyond numbers and letters that idiosyncratically escape epenthesis. We simply propose the hypothesis that numbers and letters escape epenthesis because they belong to phonologically particular categories, and draw a parallel between this fact and the present neuropsychological dissociation. 
were heavily affected by phonological errors. We now consider other potential accounts of why number words should constitute a relevant category at the phonological level. At least three peculiar features of numbers may be responsible for their special status within the word production system: the specific semantic domain they refer to (quantities), the fact that they form an overlearned series of words, and the special combinatorial syntax that enables them to compose multi-digit numerals. The present study alone is not sufficient to determine which of these properties, if any, is responsible for the selective sparing phenomenon that we have reported. However, we try to suggest how each of these alternative theories could be empirically tested in further research.

\section{Number Words and Lexicosemantic Categories}

A first specific property of number words is that they refer to a narrow category-specific semantic domain that can be selectively spared or impaired by a brain lesion (Cipolotti, Butterw orth, \& Denes, 1991; Dehaene \& Cohen, 1997; Goodglass, Klein, Carey, \& James, 1966). It is now well established that word finding and word comprehension difficulties can affect differentially categories such as nouns vs. verbs, tools vs. animals or familiar people, etc. Such evidence, along with functional brain imaging studies, suggests that, considering only nouns, word forms and concepts activate one another through convergent two-way projections to the left inferotemporal region (H. Damasio et al., 1996). These convergence points are the neural substrate of word lemmas, as defined in the functional framework outlined earlier (Caramazza, 1996). Furthermore, the temporal convergence zone can be subdivided anatomically according to conceptual domains (A.R. Damasio \& Tranel, 1993; H. Damasio et al., 1996). It has been proposed that, in the case of action verbs, the binding of word forms and concepts is achieved by the frontal rather than by the temporal lobe (A.R. Damasio \& Tranel, 1993; Denes, Meneghello, Vallese, \& Vanelli, 1996). In summary, the cerebral layout of word lemmas is organised according to semantic (and possibly grammatical) categories. It is possible that at least some of these topographical distinctions are further propagated along the speech production pathway, down to the level of word forms or lexemes. On this account, the lexemes of a given category of words, such as numerals in the present case, could be selectively impaired or spared, yielding categoryspecific phonological errors.

However it should be noted that, aside from the present case, evidence for such a categorical organisation at the lexeme level is as yet extremely limited. A few case reports suggest that closed-class words may occasionally escape phonological distortions (Butterworth, 1979; Coslett, Gonzalez-Rothi, \& Heilman, 1984; Friederici \& Schoenle, 1980). Friederici and Schoenle studied a patient with Wernicke's aphasia (case 1) who, when reading aloud lists of words, made $88 \%$ errors (including $76 \%$ neologisms) with open-class words, 
but only $29 \%$ errors (including $24 \%$ neologisms) with closed-class words. No specific information was provided concerning the patient's performance with number words. We are not aware of reports of selective sparing or impairment of other word categories at the phonological level. As yet, therefore, there is little reason to generalise from numbers and closed-class words to the whole lexicon, or to propose that phonological encoding relies on dissociable subsystems for different word categories, beyond these two special cases.

\section{Number Words and Automatic Speech}

Beyond their semantic specificity, an original feature of number words is that they are commonly recited as an ordered verbal series (one, two, three ...), for instance for the purpose of counting objects. Young children learn number words by reciting the series, even before comprehending the correspondence with abstract quantities (Wynn, 1990). The overpractised series of number words is part of what is often called "automatic" or "nonpropositional" speech, along with other series such as the alphabet, the days of the week, elementary arithmetic facts (e.g. "two times three ... six"), etc. A relative sparing of automatic speech in otherwise severely aphasic patients has repeatedly been observed (e.g. Henschen, 1926; Lum \& Ellis, 1994), even in patients with a severe jargon (Cummings, Benson, Walsh, \& Levine, 1979), and standard language batteries include an assessment of this particular speech modality. As an illustration of the ability to access number words by a pathway dedicated to automatic speech, aphasic patients may be able to name arabic digits or spelled-out numerals only through serial counting (Cohen et al., 1994; Dehaene \& Cohen, 1991; Gazzaniga \& Hillyard, 1971). Similarly, patients with Gerstmann's acalculia are unable to solve elementary problems such as 7-3, but can still provide the result of problems overlearned as verbal automatisms, such as "three times six, eighteen" (Dehaene \& Cohen, 1997).

It may therefore be hypothesised that number words were spared by the jargon because, in addition to their use in normal propositional speech, they can be uttered in the context of automatic speech. We do not claim that our patient resorted to a counting strategy when reading aloud numerals. There was indeed no clinical indication that he did so. We only suggest that words that have been learned as automatic speech might benefit from particular access mechanisms, even when produced out of the context of overlearned word series. This hypothesis has the advantage of readily accounting for the parallel sparing of letter reading. Whereas letters can be named individually, just like any other visual object, children also learn their names by rote in a fixed order. Adults often recite this series to determine the relative position of two letters in the alphabet, for instance when looking up a word in a dictionary. As reported earlier, our patient did not make a single phonological error when naming letters. His only error in 26 trials consisted in naming letter $\mathrm{R}(/ \mathrm{er} /)$ as $\mathrm{D}(/ \mathrm{de} /)$. 
Although letter names may seem trivially simple, they are phonologically comparable, and sometimes identical, to ordinary monosyllabic words (e.g. C and sea, $\mathrm{B}$ and bee). The patient made as many as $27 / 43$ (62.8\%) errors with monosyllabic words with a CV or VC structure comparable to that of letter names (6/13 with pictures and 21/30 with written words). Thus letter names, just like number words, significantly escaped the errors affecting ordinary words of a matched complexity $\left[\chi^{2}(1)=24.1, P<.0001\right]$.

The associated sparing of letters and numbers suggests that perhaps number words were not spared as such, but only because the neural systems underlying the production of automatic speech were intact (Cummings et al., 1979). Unfortunately, we have no data concerning the patient's behaviour with other instances of automatic speech, such as days of the week, months of the year, nursery rhymes, etc. The relatively preserved automatic speech in aphasics has been often ascribed to the intact right hemisphere (e.g. Graves \& Landis, 1985; Henschen, 1926; Kinsbourne, 1971). Alternatively, it has also been proposed that left cortico-subcortical loops play a role in verbal automatisms amidst other familiar motor sequences (Dehaene \& Cohen, 1997; Houk \& Wise, 1995). Whatever the correct account, the present data are compatible with the idea that the output word forms of "automatic words" rest on cerebral systems anatomically distinct from the systems that underlie ordinary propositional speech.

\section{Number Words, Letter Names, and Phonemes: The Building Blocks of Speech?}

Number words and letter names share another interesting feature beyond their role in automatic speech. They can both be combined to form complex words. Letter names can be combined to form acronyms, such as /ju/-/es/-/es//ar/ (USSR). Similarly, number words can be combined to form complex numerals such as /twenti/-/Ori/ (23). When involved in such combinations, individual number words and letter names behave as complex phonological entities intermediate between the word and the phoneme levels. In some sense, while phonemes are the building blocks of most words, one may say that individual letter names are the building blocks of acronyms and individual number words the building blocks of complex numerals.

One may then speculate that the speech production system may have integrated the combinatorial particularities of numerals and acronyms as a functional regularity of the mapping between words and articulation patterns. Whereas most words are programmed as a sequence of phonemes, it is at least possible that the units of speech production, in the case of numerals, are entire number words. The entire sequence of phonemes making up the pronunciation of a number word (/for/) or a letter word (/ju/) might be retrieved as a distinct unit during speech production. This hypothesis would provide an explanation 
for the above-menti oned special status of number words and letters with respect to the rules of liaison and epenthesis.

In this perspective, the patient's deficit might tentatively be interpreted as affecting a general stage of processing during which the appropriate phonological units making up the word to be produced would be retrieved. Noise during this unit selection stage would result in random substitutions of inappropriate units. Entire individual number words would be substituted during number production, whereas in the case of other types of words individual phonemes would be subject to errors.

Although clearly speculative, the theory outlined here has the advantage of accounting simultaneously for all the main features of the patient's deficit, namely the word substitution errors in number reading and the phoneme substitution errors in normal word production. All other accounts of the category-specificity of the jargon need to make the ad hoc hypothesis that two functionally unrelated deficits were independently responsible for the word and number reading impairments. The postulation of two functionally independent deficits seems implausible, however, because it would be a remarkable coincidence if the phoneme selection deficit spared precisely the same lexical category (number words) that was exclusively affected by word selection errors. Further work should tell whether the more economical concept of a single combinatorial process occurring at multiple levels during word production (single phonemes, letter names, or individual number words) is a viable theoretical construct.

Manuscript first received 9 September 1996 Revised manuscript received 15 September 1997

Revised manuscript accepted 16 October 1997

\section{REFERENCES}

Anderson, S.W., Damasio, A.R., \& Damasio, H. (1990). Troubled letters but not numbers: Domain specific cognitive impairment following focal damage in frontal cortex. Brain, 113, 749-766.

Badecker, W., Miozzo, M., \& Zanuttini, R. (1995). The two-stage model of lexical retrieval: Evidence from a case of anomia with selective preservation of grammatical gender. Cognition, 57, 193-216.

Best, W. (1996). When rackets are baskets but baskets are biscuits, where do the words come from? A single case study of formal paraphasic errors in aphasia. Cognitive Neuropsychology, $13,443-480$.

Butterworth, B. (1979). Hesitation and production of verbal paraphasias and neologisms in jargon aphasia. Brain and Language, 8, 133-161.

Butterworth, B. (1992). Disorders of phonological encoding. Cognition, 42, 261-286.

Campbell, J.I.D., \& Clark, J.M. (1988). An encoding-complex view of cognitive number processing: Comment on McCloskey, Sokol, \& Goodman (1986). Journal of Experimental Psychology: General, 117, 204-214.

Caramazza, A. (1996). The brain's dictionary. Nature, 380, 485-486. 
Cipolotti, L., Butterworth, B., \& Denes, G. (1991). A specific deficit for numbers in a case of dense acalculia. Brain, 114, 2619-2637.

Cohen, L., \& Dehaene, S. (1991). Neglect dyslexia for numbers? A case report. Cognitive Neuropsychology, 8, 39-58.

Cohen, L., Dehaene, S., \& Verstichel, P. (1994). Number words and number nonwords: A case of deep dyslexia extending to arabic numerals. Brain, 117, 267-279.

Content, A., Mousty, P., \& Radeau, M. (1990). Brulex, une base de données lexicales informatisée pour le français écrit et parlé. L'année Psychologique, 90, 551-566.

Coslett, H.B., Gonzalez-Rothi, L.G., \& Heilman, K.M. (1984). Reading: Selective sparing of closed-class words in Wernicke's aphasia. Neurology, 34, 1038-1045.

Cummings, J.L., Benson, D.F., Walsh, M.J., \& Levine, H.L. (1979). Left-to-right transfer of language dominance: a case study. Neurology, 29, 1547-1550.

Damasio, H., \& Damasio, A.R. (1989). Lesion analysis in neuropsychology. Oxford: Oxford University Press.

Damasio, A.R., \& Tranel, D. (1993). Nouns and verbs are retrieved with differently distributed neural systems. Proceedings of the National Academy of Sciences of the USA, 90, 4957-4960.

Damasio, H., Grabowski, T.J., Tranel, D., Hichwa, R.D., \& Damasio, A. (1996). A neural basis for lexical retrieval. Nature, 380, 499-505.

Dehaene, S. (1995). Electrophysiological evidence for category-specific word processing in the normal human brain. NeuroReport, 6, 2153-2157.

Dehaene, S., \& Cohen, L. (1991). Two mental calculation systems: A case study of severe acalculia with preserved approximation. Neuropsychologia 29, 1045-1074.

Dehaene, S., \& Cohen, L. (1995). Towards an anatomical and functional model of number processing. Mathematical Cognition, 1, 83-120.

Dehaene, S., \& Cohen, L. (1997). Cerebral pathways for calculation: Double dissociations between Gerstmann's acalculia and subcortical acalculia. Cortex, 33, 219-250.

Deloche, G., \& Seron, X. (1987). Numerical transcoding: A general production model. In G. Deloche \& X. Seron (Eds.), Mathematical disabilities: A cognitive neuropsychological perspective (pp. 137-170). Hillsdale, NJ: Lawrence Erlbaum Associates Inc.

Denes, G., Meneghello, F., Vallese, F., \& Vanelli, L. (1996). Task-dependent noun retrieval deficit: An experimental case study. Neurocase, 2, 35-43.

Ellis, A.W., Miller, D., \& Sin, G. (1983). Wernicke's aphasia and normal language processing: A case study in cognitive neuropsychology. Cognition, 15, 111-114.

Friederici, A.D., \& Schoenle, P.W. (1980). Computational dissociation of two vocabulary types: Evidence from aphasia. Neuropsychologia, 18, 11-20.

Gazzaniga, M.S., \& Hillyard, S.A. (1971). Language and speech capacity of the right hemisphere. Neuropsychologia, 9, 273-280.

Geschwind, N. (1965). Disconnexion syndromes in animals and man: Part II. Brain, 88, $585-644$.

Goodglass, H., Klein, B., Carey, P., \& James, K.J. (1966). Specific semantic word categories in aphasia. Cortex, 2, 74-89.

Graves, T., \& Landis, T. (1985). Hemispheric control of speech expression in aphasia. Archives of Neurology, 42, 249-251.

Henschen, S.E. (1926). On the function of the right hemisphere of the brain in relation to the left in speech, music and calculation. Brain, 49, 110-123.

Houk, J.C., \& Wise, S.P. (1995). Distributed modular architectures linking basal ganglia, cerebellum, and cerebral cortex: Their role in planning and controlling action. Cerebral Cortex, 2 , 95-110.

Hurford, J.R. (1987). Language and number. Oxford: Basil Blackwell.

Kinsbourne, M. (1971). The minor cerebral hemisphere as a source of aphasic speech. Archives of Neurology, 25, 302-306. 
Kohn, S.E., \& Goodglass, H. (1985). Picture naming in aphasia. Brain and Language, 24, $266-283$.

Lecours, A.R. (1982). On neologisms. In J. Mehler, E.C.T. Walker, \& M.F. Garrett (Eds.), Perspectives on mental representation. Hillsdale, NJ: Lawrence Erlbaum Associates Inc.

Levelt, W.J.M. (1989). Speaking: From intention to articulation. Cambridge, MA: MIT Press.

Levelt, W.J.M. (1992). Accessing words in speech production: Stages, processes and representations. Cognition, 42, 1-22.

Levelt, W.J.M., \& Wheeldon, L. (1994). Do speakers have access to a mental syllabary? Cognition, 50, 239-269.

Lum, C.C., \& Ellis, A.E. (1994). Is "nonpropositional" speech preserved in aphasia? Brain and Language, 46, 368-391.

Martin, A., Haxby, J.V., Lalonde, F.M., Wiggs, C.L., \& Ungerleider, L.G. (1995). Discrete cortical regions associated with knowledge of color and knowledge of action. Science, 270, 102-105.

Martin, A., Wiggs, C.L., Ungerleider, L.G., \& Haxby, J.V. (1996). Neural correlates of categoryspecific knowledge. Nature, 379, 649-652.

McCloskey, M., Sokol, S.M., \& Goodman, R.A. (1986). Cognitive processes in verbal number production: Inferences from the performance of brain-damaged subjects. Journal of Experimental Psychology: General, 115, 307-330.

Meyer, A.S. (1992). Investigation of phonological encoding through speech error analyses: Achievements, limitations, and alternatives. Cognition, 42, 181-211.

Naeser, M.A., Helm-Estabrooks, N., Haas, G., Auerbach, S., \& Srinivasan, M. (1987). Relationship between lesion extent in 'Wernicke's area' on computed tomographic scan and predicting recovery of comprehension in Wernicke's aphasia. Archives of Neurology, 44, 73-82.

Schriefers, H., Meyer, A.S., \& Levelt, W.J.M. (1990). Exploring the time course of lexical access in language production: Picture-word interference studies. Journal of Memory and Language, $29,86-102$.

Segui, J., Mehler, J., Frauenfelder, U., \& Morton, J. (1982). The word frequency effect and lexical access. Neuropsychologia, 20, 615-627.

Sevald, C.A., Dell, G.S., \& Cole, J.S. (1995). Syllable structure in speech production: Are syllables chunks or schemas? Journal of Memory and Language, 34, 807-820.

Shattuck-Hufnagel, S. (1979). Speech errors as evidence for serial-order mechanism in sentence production. In W.E. Cooper \& E.C. Walker (Eds.), Psycholinguistic studies presented to Merrill Garrett. Hillsdale, NJ: Lawrence Erlbaum Associates Inc.

Snodgrass, J.G., \& Vanderwart, M. (1980). A standardized set of 260 pictures: Norms for name agreement, image agreement, familiarity, and visual complexity. Journal of Experimental Psychology: Human Learning, 6, 174-215.

Treiman, R. (1983). The structure of spoken syllables: Evidence from novel word games. Cognition, 15, 49-74.

Verstichel, P., Cohen, L., \& Crochet, G. (1996). Associated production and comprehension deficits for names of people following left temporal lesion. Neurocase, 2, 221-234.

Wynn, K. (1990). Children's understanding of counting. Cognition, 36, 155-193. 